\title{
Fabrication of Compact Heat Exchanger with Composite Alloys
}

\author{
Barmavatu Praveen, S.Chakradhar Goud
}

\begin{abstract}
Composite alloys are said to be the materials mixture two or more components which gives more strength and effectiveness to the fabricated component where it is used. Majorly these composites are being played a vital role in consideration to heat transfer in these days. We all know that the Heat Exchanger is gadget constructed for environment friendly heat transfer from one fluid to any other in which either wall to cease them from mixing separates fluids or fluids are allowed in direct contact with each other. The exact goals of this job were to select the most satisfying materials, designs, and optimize manufacturing processes.. After fabrication, man or woman diagram idea prototypes had been examined to decide their thermal performance. Materials like SS304+Flyash and $S S 316+C u$ are used as composites alloys for fabrication of $\mathrm{CHE}$

Index Terms - Heat Exchanger, CHE, Optimize, thermal performance.
\end{abstract}

\section{INTRODUCTION}

In the present world scenario, manufacturing industries require materials, which possess lofty force to mass ratio for application in aerospace, automotive and transportation industries. The conformist equipment such as metals, alloys, ceramics and plastics are not able to meet this requirement. These problems can be overcome by use fused materials. The world is aware composite materials for several hundred years ago, which is available in form of natural composites such as wood, rocks, bamboo, etc. In ancient days, improvement in quality life made humans construct houses with mud, bricks lime with straw, which clearly gives definition composite fabric that consists two or more noticeably express constituents'. This chapter clearly illustrates sorting various types composites, its advantages, disadvantages applications. It also deals with various types matrix reinforcement substances used in metallic matrix composites and their applications.

\section{Classification of composite materials:}

A composite is structural material that consist two or more blended parts that are mixed at macroscopic level and are no longer soluble in each other. These materials can be set up by putting at least two disparate materials in such manner that they work precisely as single unit. The properties composites will be differing from their constituents. Composite materials have soft continuous phase which acts as matrix material discontinuous phase with usual strength and stronger than nonstop chapter it is called reinforcement. The mechanical property composite depends on properties its matrix reinforcement materials, the distribution and interaction among them. The classification composites mainly depends on types of medium plus support materials, their orientation, and distribution as shown in Figure The composites are classified in chief way base on type of medium plus strengthening used and their orientations.

\section{METHODOLOGY}

Dense heat exchanger manufactures the basic principles are the same for all sizes and materials. Wrinkles, side bars, dividing sheets cap sheets are placed in jigs under predefined load placed in furnace and brass to form the heat exchanger block of plate fines. During the welding process, header tanks and nozzles are welded to block, keeping the brass joints intact.

\section{A. Materials and design specifications:}

The design is done such that flow enhancement parameters fluids are taken in particular ratios desired parameters. The concentrations of these fin structures along tube are even so that during maintained velocity and pressure will be constant all along system to obtain regular flow with span time intervals taken for each fluid concentrations.

\section{B. Thermal resistivity of heat exchanger with varying alloys} material:

Table 1.1 Properties of SS304+flyash \& SS316+ Copper:

\begin{tabular}{|c|c|c|c|}
\hline & \multirow{2}{*}{ Units } & \multicolumn{2}{|c|}{$\begin{array}{c}\text { Maximum Value } \\
\text { (S.I.) }\end{array}$} \\
\cline { 3 - 4 } & (Imp.) & $\begin{array}{c}\text { SS304+ } \\
\text { flyash }\end{array}$ & $\begin{array}{c}\text { SS316+ } \\
\text { Copper }\end{array}$ \\
\hline Density & $\mathrm{lb} / \mathrm{ft} 3$ & 8.07 & 8.06 \\
\hline $\begin{array}{c}\text { Bulk } \\
\text { Modulus }\end{array}$ & $\mathrm{Gpa}$ & 152 & 134 \\
\hline $\begin{array}{c}\text { Compressive } \\
\text { Strength }\end{array}$ & $\mathrm{Mpa}$ & 310 & 205 \\
\hline $\begin{array}{c}\text { Poisson's } \\
\text { Ratio }\end{array}$ & - & 0.275 & 0.265 \\
\hline $\begin{array}{c}\text { Tensile } \\
\text { Strength }\end{array}$ & $\mathrm{Mpa}$ & 620 & 510 \\
\hline $\begin{array}{c}\text { Thermal } \\
\text { Conductivity }\end{array}$ & $\begin{array}{c}\mathrm{W} / \mathrm{m} . \\
\mathrm{K}\end{array}$ & 17 & 14 \\
\hline $\begin{array}{c}10- \\
\text { Resistivity }\end{array}$ & $\begin{array}{c}8 \text { ohm. } \\
\mathrm{m}\end{array}$ & 81 & 65 \\
\hline
\end{tabular}

Revised Manuscript Received on April 12, 2019.

Barmavatu Praveen, Research Scholar, Department of Mechanical

Engineering, Shri JJT University, Jhunjhunu, Rajasthan, India.

Dr.S.Chakradhar Goud, Professor \& Principal, Springfields Engineering college, Hyderabad, Telangana, India. 


\section{RESULTS}

A. Macrograph of eroded samples for SS304 + FLY ASHSurface macrographs of depleted SS $304+$ FLY ASH Samples with an effect angle of 30 degrees and 90 degrees are shown in Figure. In both specimens, the incision starts at Centre first and then toward edges specimens. The degenerate region created by an impact angle of 90 degrees is circular, while the region depleted at an impact angle of 30 degrees is elliptical. The depleted samples from the macrographs obviously indicate that three areas have been formed. The first zone is the most depleted central region, second zone is the least depleted region, and third zone is the least depleted region.



Figure 1. SEM micrograph of SS304+Flyash

Scanning Electron Microscope (SEM) data was acquired on the microscopic scale of the composite surface. The electrons interacted with the atoms of the material as an electron beam hit the examined surface, generating signals containing data about the topography of the surfaces and eventually providing a picture of the surface of the components.



Graph 1.1 Rate of erosion ( $\mathrm{g} / \mathrm{g}$ ) against cumulative eroding of SS 304 at $D=5.0 \mathrm{~g} / \mathrm{min}$ and $V=40 \mathrm{~m} / \mathrm{s}$

Impact angle $\left(30^{\circ}\right.$ and $\left.90^{\circ}\right)$ on shear rate at $40 \mathrm{~ms}$ impact velocity for sample SS $304+$ fly ash. Shear levels are slightly greater than 90 degrees impact angle at 30 degrees impact angle. It can be seen from the macrographs that shear rate is high during the research of original cycles, followed by a steady state shear rate at an angle of effect of 300 . At low impact angles, the shear in elastic material is greater because impacted particles generate plowing effect material is separated in scoops of shape. On the other hand, most affected particles of kinetic energy are deformed by plastic at high impact angles without actually removing it.

\section{B. SEM analysis of specimens eroded:}

Electron microscope (SEM) scanning [ JEOL (JSM-5610 LV) ] with EDAX attachment was used for SEM / EDAX degenerative ulcer surface assessment. The following statistics obviously indicate craters created on the surface of
SS 304 by the impact of erodent particles. It has been noted that with formation craters and lips, plastic deformity happens. Samples depleted under impact $30^{\circ}$ show that plowing method results in material removal. Crater formation is higher than $90^{\circ}$ impact angle as shown in Figure 1. Erosion is triggered by platelet mechanism in the situation of surface matter comparable to that outlined by Hutchings and Levy. They indicated that all three stages happen simultaneously at separate surface places in a steady state. In the initial stage, the affected cell forms vent, material is extracted or displaced from the vent. The displaced metal will be deformed by subsequent impacts in the second phase. This can lead to lateral displacement material and in highly strained regions may result in some elastic fractures. Finally, after relatively few impacts, displaced material is severely strained and separated from the surface by elastic fracture



Figure 2 Scanning of eroded SS 304 + flyash in SEM at an impact angle of $30^{\circ}$

The figure above demonstrates a zoomed part of the sample again displays one of the various constructions that build a 30 degrees impact angle composite alloy SS $304+$ flyash. It is important to note that the sample's "glittering" white parts may be non-conductive materials or the sample's tall pieces, in both cases the electrons beamed at the sample cannot reach the ground.

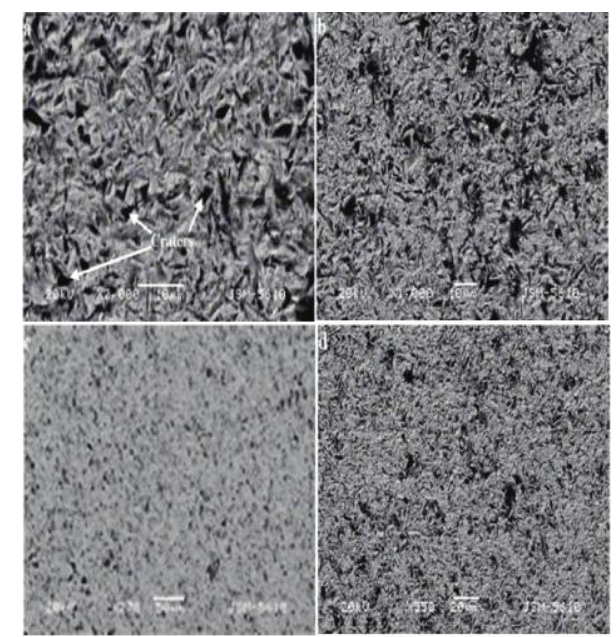

Figure 3 Scanning electron micrographs of eroded SS 304

+ Fly ash at a $90^{\circ}$ impact angle 


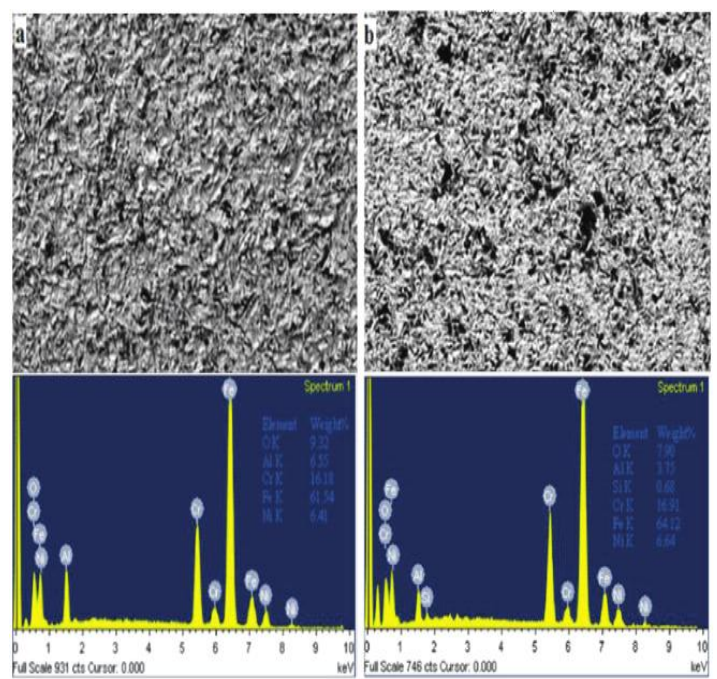

Figure 4 Shows SEM / EDAX image of SS 304 + Fly ash at $40 \mathrm{~m} / \mathrm{s}$ speed at a) $30^{\circ}$ and b) $90^{\circ}$ impact angle.

The surface was wiped before analyzing the exposed coupon to remove the thick carbon deposit coat seen above in Figure. The build-up of the combustion products seen on sections of the coupon was uneven when the exposed coupon was studied at a macroscopic scale. Some sections had deposits while others, comparable to the unexposed coupon, stayed "clean." The anticipated cause of this observation is the channeling of the condensate stream. A rough layer had developed on top of the polymer in some parts at a microscopic level from the SEM.
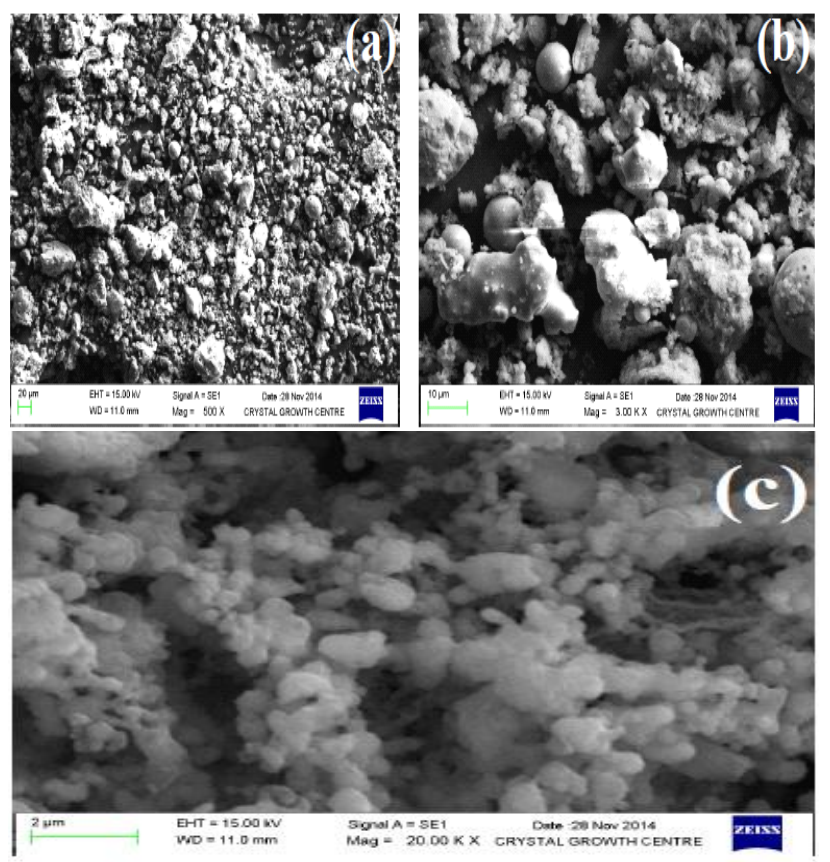

Figure 5 shows SEM images fly ash dust at unlike magnification (a) $0.5 \mathrm{KX}$ (b) $3 \mathrm{KX}$ (c) $20 \mathrm{KX}$

Dark regions in the thermography show a slower cooling rate that can be caused by bad bonding, delamination, or resin-rich regions, such as thicker $\mathrm{C}$-foam sealing. No modifications were noted in most test panel instances before and after post cure, i.e. no damage caused by thermal stress on the composites or bonding.

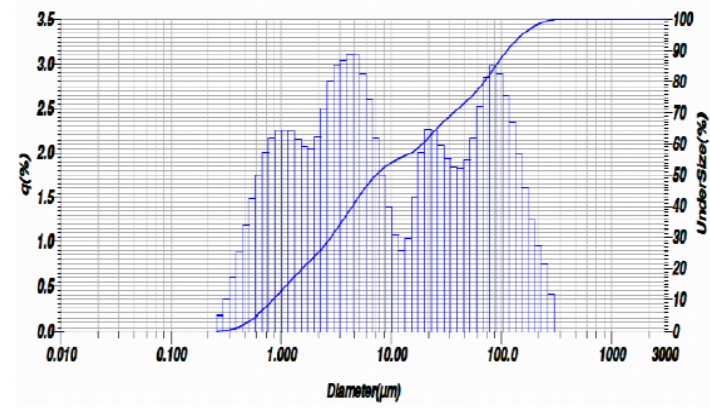

Figure 6 shows the distribution curve of fly ash particle size

While Fly Ash's price makes an appealing choice, one issue is the low thermal conductivity and its effect on the efficiency and size of the general heat transfer. As an undesirable option is considered to considerably increase the heat exchanger size, the thermal conductivity of the chosen material is essential.

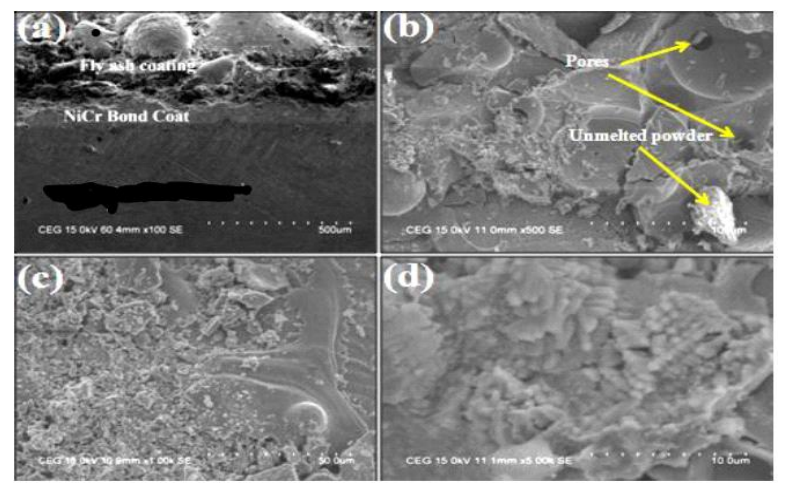

Figure 7 Shows SEM micrograph displaying surface morphology of various magnifications (a) Cross Section, 100x (b) SS304 fly ash, 500x (c) SS304 fly ash, 1 kx (d) SS304 fly ash, 5kx.



Figure 8 indicates SEM micrographs worn at separate magnifications (a) $100 x(b) 500 x(c) 1 k x(d) 5 k x$ with SS304.

\section{SEM strategy for copper-mixed SS316:}

Electrolytic copper powder ( $99.5 \%$ pure) with an average grain size of $5 \mathrm{~mm}$ was used to create copper coating on austenitic stainless steel. It illustrates the typical morphology of raw copper powder used to deposit 


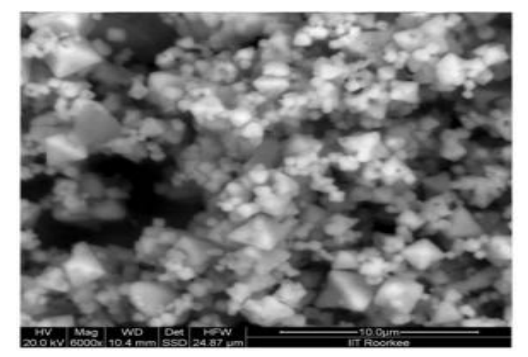

Figure 9 indicates Morphology of copper

Typical topographical surface copper withSS-316 is shown in Figure. 9. The copper deposits of surface morphology show a fairly dense, equiaxed, and homogeneous combination. This can be attributed to the volumetric warmth associated with the processing of products by microwave. The observed uneven top surface results in inaccuracies involving the starting powder manual preparation.

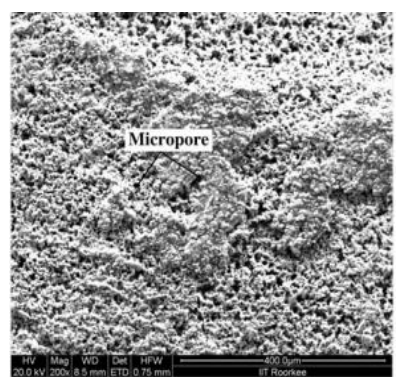

Figure 10 Typical SEM micrograph of SS316 + cu mixture

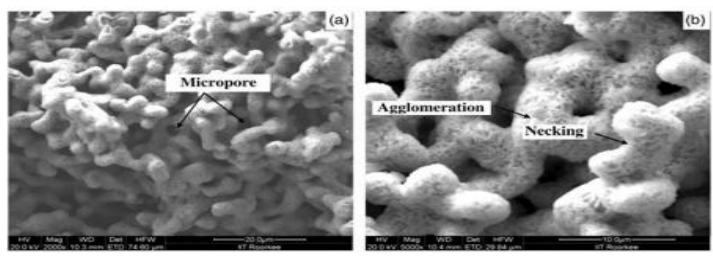

Figure 11 Typical SEM micrographs depicting growth coatings during microwave hybrid heating by interlinking fused particles

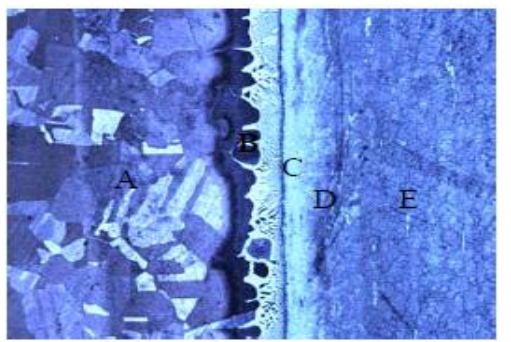

Figure 12 Metallographic photos 200x

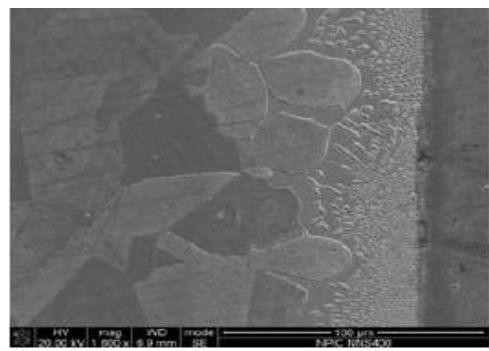

Figure.13 SEM micrograph

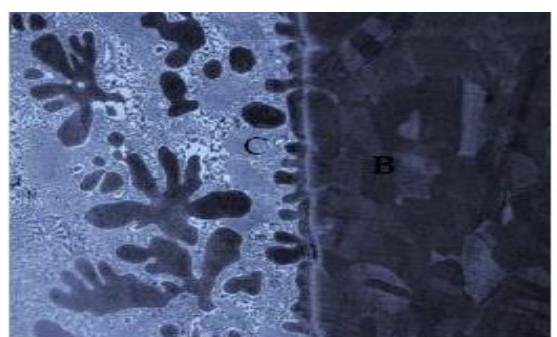

Figure .14 Corresponding to B, C 500x

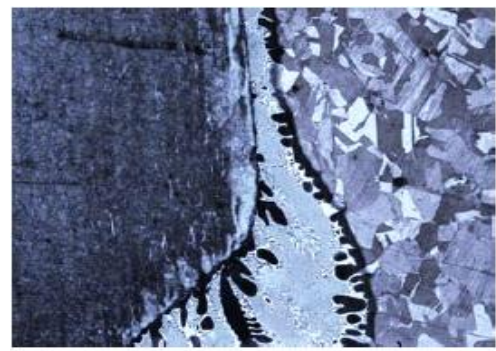

Figure.15 Microstructure morphology of wide-gap 200x

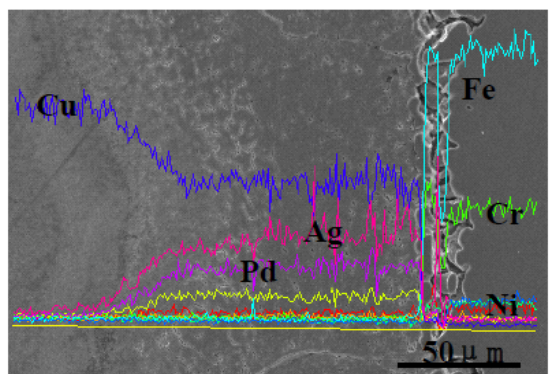

Figure 16 SEM micrograph and elemental line scan


Figure 17 SEM images of corroded carbon steel in clean (a, b) $250 \mathrm{C}$, (c, d) $600 \mathrm{C}$, (e, f) $800 \mathrm{C}$ after 15 days of exposure in $\mathrm{LiBr}-\mathrm{H} 2 \mathrm{O}$ solution.

Micrograph of fractured surface and micrograph of fractured counter surface the tensile strength of the composite alloys vs polymer composites must also be considered, which may result in thicker sections and more volume required for the composites. The nominal tensile strength of alloy $904 \mathrm{~L}$ is $88,000 \mathrm{psi}$ and the manufacturer of a thermally conductive business polymer has significance.
Published By: \& Sciences Publication

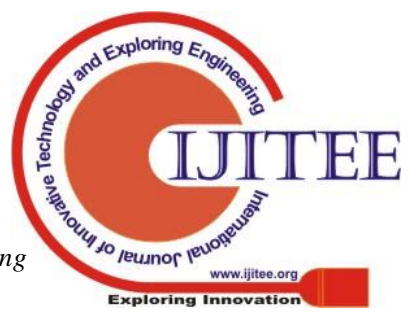




\section{CONCLUSIONS}

Compact heat exchangers with alloy materials allow the integration with high effectiveness of countless high temperature procedures. Here in the production solid warmth exchanger alloys such as SS304+FLYASH and $\mathrm{SS} 316+\mathrm{Cu}$ is enhanced with more microscopic approach where in which we found that SS304 mixed with Fly ash is having better rate of sustainability which can be used in production of solid warmth exchanger.

\section{REFERENCES}

1. L. E. Khoong, Y. M. Tan, and Y. C. Lam, "Overview on Fabrication ofThree-Dimensional Structures in Multi-Layer Ceramic Substrate," J. Eur.Ceram. Soc., 30 1973-1978 (2010).

2. R. Lenk, "Product and Process Oriented Shaping Techniques for AdvancedCeramics at the Example of Ceramic Injection Molding and Extrusion,"Ceram. Forum Int., 87 [4] E17-E20 (2010)

3. Burns, J.R. and Jachuck, R.J.J. "Condensation study use angry ribbed Polymer Film solid warmth exchanger," Applied Thermal Engineering, Vol. 21, pp. 495-510, 2015

4. Christmann, J.B.P. Krätz, L.J. Bart, H.-J. "Falling Film Evaporation with Polymeric Heat Transfer Surfaces," Desalination, Vol. 308, pp. 56-62, January 2013

5. Shah, R. K. and Webb, R. L. Compact and Enhanced Heat Exchangers, in J. Taborek, G. F. Hewitt and N. Afgan (Eds), Heat Exchangers - Theory and Practice McGraw Hill, New York, 425-468,2017

6. Cevallos, J.G. Bergles, A.E. Bar-Cohen, A. Rodgers P. and Gupta. S.K. "Polymer warmth exchangers narration, prospect, and Challenges," Heat Transfer Engineering, Vol. 33, no. 13, pp. 1075-1093, May 2017 